\title{
Precision-structural Design for Scanning Probe Microscopes
}

\author{
Moo-Yeon Lee ${ }^{1}$, Jaesool Shim ${ }^{2}$ and Dong-Yeon Lee ${ }^{2^{*}}$ \\ ${ }^{1}$ School of Mechanical Engineering, Korea University \\ ${ }^{2}$ School of Mechanical Engineering, Yeungnam University \\ 주사탐침현미경을 위한 정밀 구조 설계
${ }^{1}$ 고려대학교 기계공학부
${ }^{2}$ 영남대학교 기계공학부 \\ 이무연 ${ }^{1}$, 심재술 ${ }^{2}$, 이동연 $2^{*}$
}

\begin{abstract}
Nano-measurement systems such as scanning probe microscopes should be protected against external disturbances. For the design of a scanning probe microscope, the external vibrations need to be characterized and the vibrational properties of the structural frame itself should be modeled. Also, the influences of the external vibration on the apparatus need to be known for its utmost precision. In this paper, the combined vibrational-characteristics of the floor and the structural frame are analyzed and experimentally investigated.
\end{abstract}

요 약 주사탐침현미경과 같은 나노 측정 시스템은 외란으로부터 보호를 받아야만 한다. 주사탐침현미경의 설계를 위해 외부 진동진동의 특성을 파악해야 하고, 구조프레임 자체의 진동 해석 해야 한다. 또한 장치의 최고 정밀도를 파악하기 위하여, 외부진동의 영향을 분석해야 한다. 본 논문에서는 바닥진동과 구조프레임을 동시에, 진동 분석과 실 험을 통하여 진동 특성을 조사하였다.

Key Words : Structural frame design, Scanning probe microscope, Vibration isolator, Transmissibility

\section{Introduction}

Ultra-precision measuring apparatuses need to be constructed with the state-of-the-art components for their best performances[1]. Even though the developed apparatus shows the expected performances in the laboratory conditions, the unexpected noise could be arisen in the practical site[2]. The possible causes for the error are external disturbances such as a thermal fluctuation, an electro-magnetic influence, an acoustic excitation and a floor vibration caused by the laboratory utilities and the people's walking[3]. Among the disturbances, the suppression of the floor vibration is indispensable to the most precise apparatuses. In this paper, the floor vibration properties are experimentally characterized and their influences on the scanning probe microscope are evaluated. Moreover, the design strategy for the structural frame combined with the vibration isolator is established.

\section{Design of the structural frame}

Prior to a detailed design of frames for a scanning probe microscope (SPM) such as an atomic force microscope, the vibrational characteristics of the floor should be known. To design and analyze frames, the floor vibration is measured in typical laboratory conditions, as shown in Fig. 1. From the result, the floor vibrational level is seen to vary with the frequency and the

This research was supported by Future-based Technology Development Program(Nano Fields) through the National Research Foundation of Korea(NRF) funded by the Ministry of Education, Science and Technology (2010-0019110)

*Corresponding Author : Lee, Dong-Yeon (dylee@ynu.ac.kr)

Received October 11, 2010

Revised November 10, 2010

Accepted November 19, 2010 
vibrational level is of the order of $10^{-8}$ meters. Typically, buildings vibrate at frequencies between 10 and 100 Hz. These vibrations are excited by machines that run at or near the line frequency and by the associated harmonics and sub-harmonics. The frame, walls, and floors of a building mostly undergo shear and bending vibrations that usually resonate at frequencies between 15 and $25 \mathrm{~Hz}$. These values are directly related to the maximum floor load with standard values of 500 1000 $\mathrm{kg} / \mathrm{m}^{2}$ in modern buildings[1]. The vibrational spectra of buildings therefore frequently contain their largest maxima near the third sub-harmonic of the line frequency, i.e., 15 $\sim 20 \mathrm{~Hz}$, as in the example shown in Fig. 1.

The influence on the tip-to-sample distance of the external perturbations described above can be reduced through damping mechanisms and/or sufficient stiffness of the basic SPM structure sketched in Fig. 2. The stiffer is the structure, the lesser is the required damping.

To analyze the SPM structure that is incorporated with a vibration-isolation system, a mathematical model is depicted as in Fig. 3. Here, $Z_{g}, Z_{b}$, and $Z$ are the displacements of the floor(ground), base of the isolator, and tip of the SPM with respect to the inertial space (I.S.), respectively, while $d$ is the relative displacement between the tip and the sample. The most important parameter is $d / Z_{g}$.

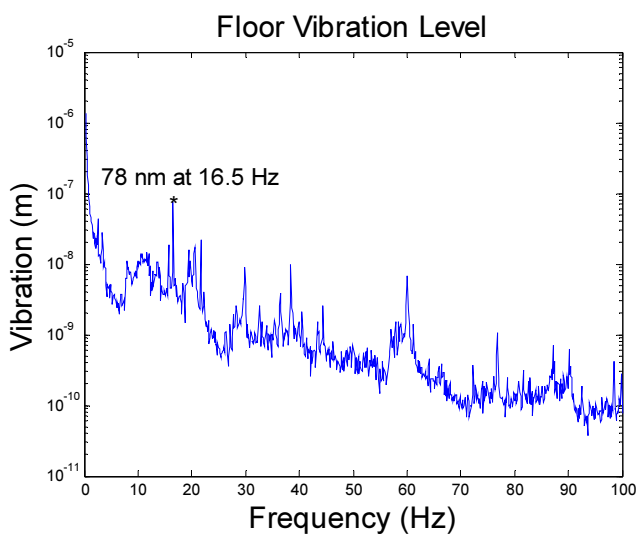

[Fig. 1] Vibration spectrum of a typical floor in laboratory conditions. As indicated, the maximum vibration is $78 \mathrm{~nm}$ at $16.5 \mathrm{~Hz}$.

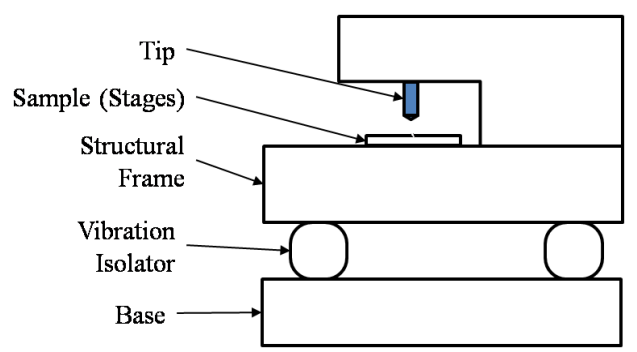

[Fig. 2] Schematic diagram of the scanning probe microscope

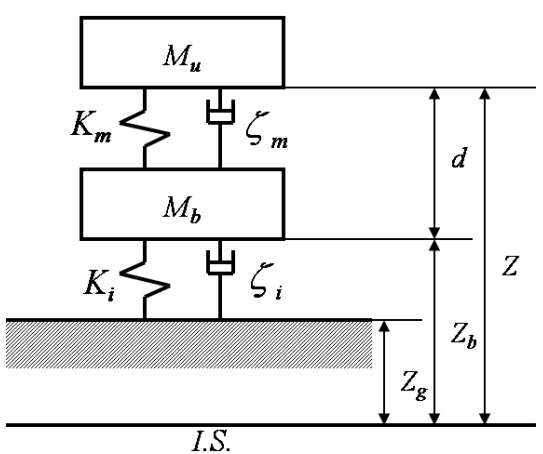

[Fig. 3] Mathematical model of AFM structure and vibration isolation system. $M_{u}$ is the total mass supported by frames, $K_{m}$ and $\zeta_{m}$ is the stiffness and damping of the structure respectively, $M_{b}$, $K_{i}$ and $\varsigma_{i}$ is the base mass, stiffness and damping of the vibration isolation system, respectively

The analysis of the SPM structure is summarized as follows.

$$
\begin{aligned}
& M_{u}\left(\ddot{d}+\ddot{Z}_{b}\right)=-\zeta_{m} \dot{d}-K_{m} d \\
& M_{b} \ddot{Z_{b}}=\zeta_{m} \dot{d}+K_{m} d-\zeta_{i}\left(Z_{b}-\dot{Z}_{g}\right)-K_{i}\left(Z_{b}-Z_{g}\right) \\
& \mu_{m}=\frac{d}{Z_{b}}=\gamma \frac{\left(f_{g} / f_{m}\right)^{2}}{\sqrt{\left(1-\frac{f_{g}^{2}}{f_{m}^{2}}\right)^{2}}+\left(\frac{\zeta_{m}}{\pi} \frac{f_{g}}{f_{m}}\right)^{2} \frac{M_{b}}{M_{b}+M_{u}}} \\
& \left(\text { Here, } \gamma=\frac{M_{b} \zeta_{m} \sqrt{1+\left(4 \zeta_{m}\right)^{2}}}{2 \pi^{2}\left(M_{b}+M_{u}\right)}\right)
\end{aligned}
$$

In the above, $\mu_{m}$ is the transmissibility from the base to the relative displacement between the tip and the 
sample, $g$ is the proportionality constant, fg is the ground frequency, and $f_{m}=(1 / 2 \pi)\left(K_{m} / M_{u}\right)^{0.5}$, which is the natural frequency of the frame. An example plot of $\mu \mathrm{m}$ is presented in Fig. 4.

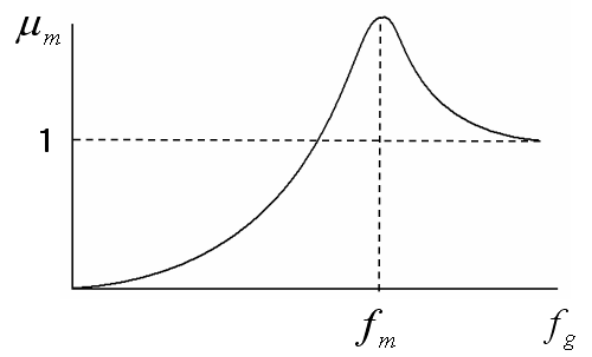

[Fig. 4] An example plot of $\mu_{m}$

From Fig. 4, for $f_{g}<f_{m}$, the response of the typical SPM frame is seen to be less than unity and increasing with the external perturbation frequency; this implies lesser sensitivity than at higher frequencies. For $f_{g}=f_{m}$, the response is equal to the base excitation that needs the vibration isolator. The modeling of the vibration isolator is as follows[4,5].

$$
\mu_{i}=\frac{Z_{b}}{Z_{g}}=\sqrt{\frac{1+\left(2 \zeta_{i} f_{g} / f_{i}\right)^{2}}{\left(1-\left(f_{g} / f_{i}\right)^{2}\right)^{2}+\left(2 \zeta_{i} f_{g} / f_{i}\right)^{2}}}
$$

In the above equations, $f_{i}=(1 / 2 \pi)\left(K_{i} / M_{u}+M_{b}\right)^{0.5}$, which is the natural frequency of the isolator. A typical example of $\mu_{i}$ is shown in Fig. 5.

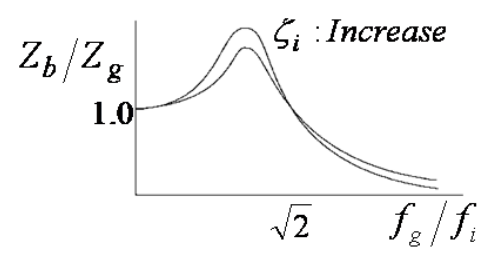

[Fig. 5] An example plot of $\mu_{i}$

The value of $\mu_{i}$ is unity at $f_{g}=(2)^{0.5} f_{i}$ and as $\zeta_{i}$ increases, $\mu_{i}$ increases. The purpose of the vibration isolator in precision instruments is to reduce the level of floor vibration for frequencies that exceed the natural frequency of the vibration isolator. Accordingly, the relative displacement $(d)$ between the tip and the sample with respect to the floor (ground) vibration is calculated as follows.

$$
\begin{aligned}
\mu & =\frac{d}{Z_{g}}=\frac{d}{Z_{b}} \times \frac{Z_{b}}{Z_{g}} \\
& =\mu_{m} \times \mu_{i}
\end{aligned}
$$

Using Eqs. (1) (3), the response of the SPM structure is simulated as shown in Fig. 6. Here, $f_{m}$ is determined from the simulation result of the designed structural frame, as shown in Fig. 7 and $f_{i}$ is selected from the real measurement of the transmissibility of the vibration isolator, as shown in Fig. 8. As a guide for the frame design, the resonant frequency of the vibration isolator should be kept low while the resonant frequency of the structural frame should be kept high.

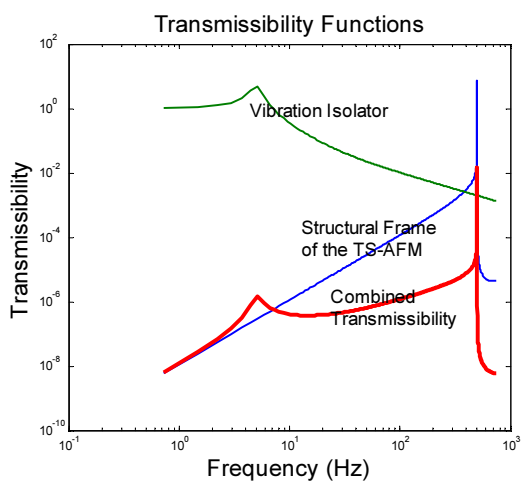

[Fig. 6] Simulation results of the combined transmissibility. fi and $\mathrm{fm}$ is 5 and $467 \mathrm{~Hz}$, respectively

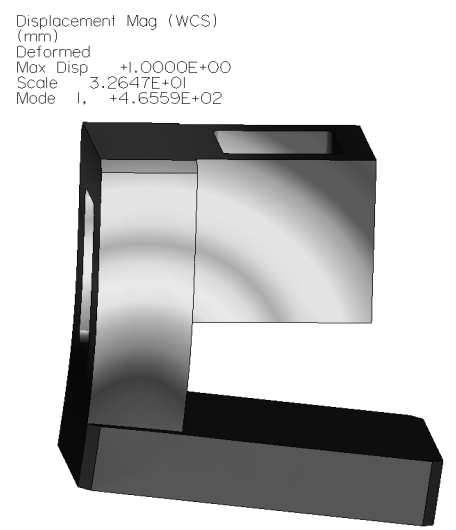

[Fig. 7] 40 First resonant frequency $(466 \mathrm{~Hz})$ of the designed structural frame of the TS-AFM 


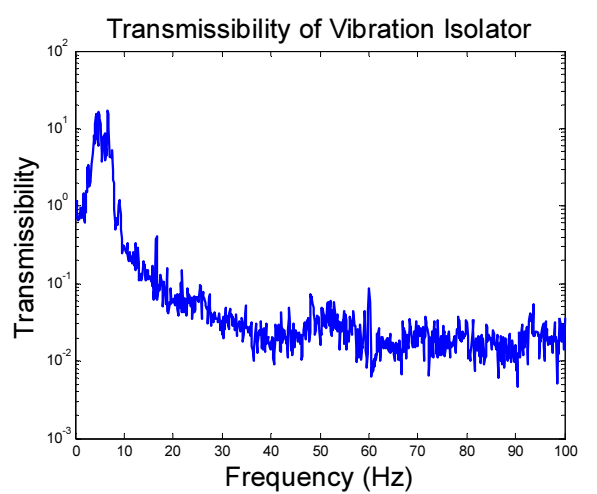

[Fig. 8] Transmissibility of the vibration isolator

Finally, to evaluate the relative displacement $(d)$ between the tip and the sample with respect to the floor vibration, the actual response $(d)$ to the floor vibration, which is experimentally acquired, is calculated through the result of Fig. 1 and Eqs. (1) (3). From the result of Fig. 9, the order of magnitude is $10^{-13}$ meters, which confirms the highly stiff design of the structural frame of the SPM.

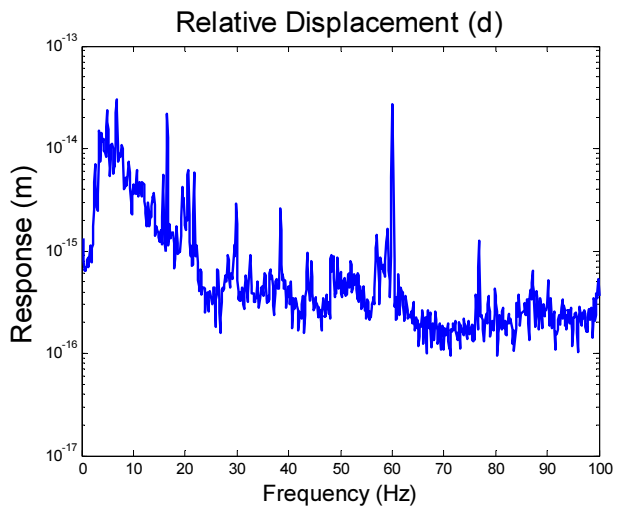

[Fig. 9] Relative displacement between the tip and sample w.r.t. the floor vibration after suppressing via the vibration isolator

\section{Conclusions}

The floor vibration characteristics are evaluated and analyzed. To suppress the floor vibration, the vibration isolator is used and the stiff structural frame is recommended. For the exact estimate of the apparatus noise, the theoretical equations of the vibration isolator, the structural frame and their combined effect are derived and simulated with some experimental measurements. The frame, walls, and floors of a building mostly undergo shear and bending vibrations $(\sim 100 \mathrm{~nm})$ that usually resonate at frequencies between 15 and $25 \mathrm{~Hz}$. Their influences on the relative displacement between the tip and the sample after suppression via the vibration isolator (5 $\mathrm{Hz}$ resonance) are the order of magnitude is $10^{-13}$ meters errors with the proper structural frame design (467 $\mathrm{Hz}$ resonance). The design strategy described in this paper would be helpful for the design of state-of-the-art precision equipments.

\section{References}

[1] Kindt, J. H., Fantner, G. E., Cutroni, J. A., and Hansma, P. K., "Rigid design of fast scanning probe microscopes using finite element analysis", Ultramicroscopy, Vol.100, No.3/4, pp. 259-265, 2004.

[2] Bessason, B., Madshus, C., Froystein, H. A., Kolbjornsen, H., "Vibration criteria for metrology laboratories", Measurement science and technology, Vol. 10, No. 11, pp. 1009-1014, 1999.

[3] Paul, C. R., "Structural Design of Semiconductor Manufacturing Facilities", Proceedings of Construction congress $V$ : managing engineered construction in expanding global markets, pp.186-192, 1997.

[4] Park, S. and Quate, C. F., "Theories of the feedback and vibration isolation systems for the scanning tunneling microscope", Review of Scientific Instruments, Vol.58, No.11, pp. 2004-2009, 1987.

[5] Lee, Jeong-Ick, "The mechanical dither design of navigation guide structure", Journal of the Korea Academia-Industrial cooperation Society, Vol. 11, No. 6, pp. 1949-1954, 2010. 
Moo-Yeon Lee

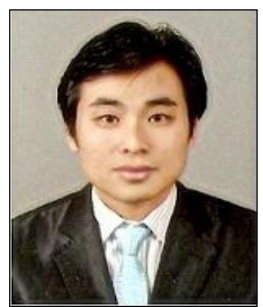

- Feb. 2003 : Dept. of Mech. Eng., Korea Univ. (Master's Degree)

- Feb. 2010 : Dept. of Mech. Eng., Korea Univ. (Ph.D.)

- Mar. $2010 \sim$ Current : Dept. of Mech. Eng., Korea Univ. (Research Professor)

$<$ Research Interests $>$

Heat and mass transfer, Bio-fluidics, Micro-fluidics, New\&Renewable energy conversion system

\section{Jaesool Shim}

[Regular member]

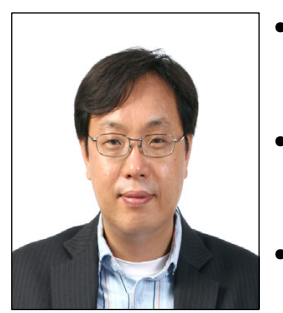

- Feb. 1997 : Dept. of Mech. Eng., POSTECH (Master's Degree)

- Dec. 2007 : Dept. of Mech. Eng., Washington State University (Ph.D.)

- Jan. $2008 \sim$ Aug. 2008 : Harvard-MIT (Postdoc)

- Sept. $2008 \sim$ Current : School of Mech. Eng., Yeungnam University (Professor)

$<$ Research Interests $>$

Nano-Bio application, protein separation chip, electrophoresis, pano/Mems temperature detection measurement,
Dong-Yeon Lee

[Regular member]
- Feb. 1999 : Dept. of Mech. Eng., KAIST (Master's Degree)

- Feb. 2007 : Dept. of Mech. Eng., KAIST (Ph.D.)

- Mar. $2007 \sim$ Aug. 2008 : Korea Electrotechnology Research Institute (Senior Researcher)

- Sept. $2008 \sim$ Current : School of Mech. Eng., Yeungnam University (Professor)

$<$ Research Interests $>$

Nano-mechatrinics, Nano-design, Scanning-Probe Microscope, Nano-lithography 